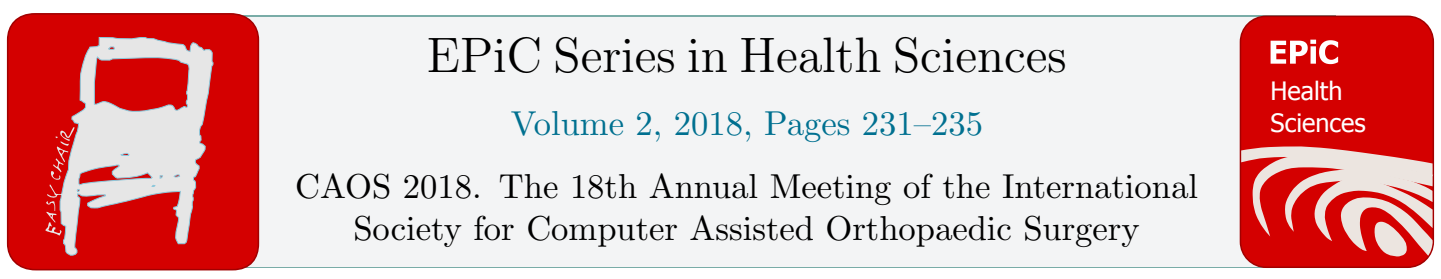

\title{
Robot Assisted Transforaminal Percutaneous Endoscopic Lumbar Discectomy
}

\author{
Han WANG MD ${ }^{1}$, Yajun LIU MD ${ }^{1}$, Mingxing FAN ${ }^{1}$, Jile JIANG MD ${ }^{1}$, Wei TIAN \\ $\mathrm{MD}, \mathrm{PhD}^{1 *}$ \\ 1,* Department of Spine Surgery, Beijing Jishuitan Hospital, Beijing, 100035, China, \\ weitianjst@126.com
}

\section{INTRODUCTION}

Percutaneous endoscopic spine surgery is popular in recent years because of its minimally invasive manner. After transforaminal approach presented by Kambin in the late 1980s, many specific methods were described to establish an accurate and feasible approach to the target disc. Among them, the techniques of Yeung ${ }^{[1]}$, Hoogland ${ }^{[2]}$ and Ruetten ${ }^{[3]}$ are the most famous ones and each has different design and indications. However, no consensus have been made because of the debated clinical results, steep learning curves, and pitfalls that exist in each approach. Guide needle insertion and subsequent working channel building remain a challenging procedure. Poor accuracy may lead to poor safety as the nerve root and dura are at risk. Many surgeons attempted to optimize the procedure, but few researches have integrated computer-assisted navigation with tPELD (transforaminal percutaneous endoscopic lumbar discectomy). It is time to bring our surgical robot into the field.

\section{MATERIALS AND METHODS}

TianJi Robot ${ }^{\circledR}$ was co-designed by Beijing Jishuitan Hospital and Tinavi Medical Technologies. The team of Prof. Wei Tian have performed nine cases of robotic guided tPELD surgeries until 2017. All patients suffered from sciatica caused by lumbar disc herniation of different levels and positions. Lumbar instability, spinal canal stenosis, recurrent or multiple segments herniation and far lateral herniation were excluded. Patient were followed up one time at three months after surgery. Visual Analog Scale/VAS (pre-operative, one day post-operative, three months post-operative), 
Oswestry Disability Index/ODI (pre-operative, three months post-operative), and modified MacNab criteria were recorded to assess clinical effect.

Each patient was placed in a lateral decubitus position (the first one) or a prone position (the remaining eight). Anesthesia methods consisted of $1 \%$ local lidocaine infiltration with intravenous sedation. Patient tracker was firmly placed on the low back region. A set of intraoperative three-dimensional images was taken and transmitted into TianJi Robot system on which puncture trajectory could be planned by surgeons. Point A (where posterior rim of superior endplate of the lower vertebra met the center of base of protruded disc) and point B (the ventral lateral rim of superior facet) were identified on the $3 \mathrm{D}$ planning system so that the line was decided. The robotic arm was then automatically moved to planned position under the guidance of the optical tracking system which located the relative position of robotic arm to the patient. After inserting a guide wire through the robotic arm, a $0.8 \mathrm{~mm}$ skin incision was cut around the wire. We now preferred to take AP and lateral projections to make sure the ideal position was arrived (Figure 1). Trephine and dilators were subsequently inserted. After placement of working cannula and endoscope, the protruded nucleus pulposus was carefully identified and extracted under direct vision.

Statistical analysis was operated by SPSS 19.0 software (SPSS Inc, Chicago, IL). Preoperative and post-operative VAS and ODI were compared by paired t tests. $\mathrm{P}<0.05$ was regarded as significant difference.

\section{RESULTS}

For patient No.2, we failed to acquire adequate 3D images because of severe obesity (BMI>35). As the index level, patient tracker and robotic arm tracker could not be observed in a single fluoroscopy, we converted the surgery into open. The data of eight patients were analyzed (Table 1). Both one day and three months VAS for sciatica after surgery were significantly reduced than the one before $(p<0.01, p<0.01)$. Postoperative ODI was also reduced $(\mathrm{p}<0.01)$. According to modified MacNab criteria, 4 patients selected excellent, 3 patients selected good, while 1 patient had poor result because of recurrent symptom at three months. In one case, two attempts of scanning and planning were required to get an acceptable trajectory.

\section{DISCUSSION}

In China, tPELD is a well-known procedure and expanding rapidly in recent years. However, there is still no strong evidence that tPELD is as effective and safe as open microdiscectomy. Clinical outcome heavily relied on the experience of surgeon. Complications reported include nerve root injury or irritation, dural tears, repetitive puncture, discitis, intracranial hypertension, bowel perforation, and recurrence. The 
most important step is to find an accurate pathway to the targeted lesion ${ }^{[4,5]}$. Fan ${ }^{[6]}$ reported an extracorporeal navigation using a set of surface locator and puncture device. Choi ${ }^{[7]}$ and $\mathrm{Wei}^{[8]}$ reported $\mathrm{X}$-ray plus $\mathrm{MRI}$ and $\mathrm{O}$-arm navigation respectively. However, these techniques were still based on repetitive intraoperative fluoroscopy and surgeon's experience, but not a computer. No robot assisted tPELD has been reported yet.

Combining intraoperative 3D navigation and robot techniques, TianJi Robot was originally designed to insert pedicle screws. That is why a shape of screw exists on the planning interface. The initial feasibility and accuracy of robot assisted tPELD were confirmed by this study. For patient No.1, we need second scanning and planning because the patient twisted his body during the first puncture. The deviation increased to more than $2 \mathrm{~mm}$ that was not acceptable. For that reason, prone positions were chose for the remaining eight patients. For patient No.5, no specific reason was found to explain the recurrence. We performed an open microdiscectomy three months after surgery.

This study had some drawbacks. First, it was a very early stage, feasibility study. No control group was investigated. Second, long-term postoperative follow up should be assessed for clinical effectiveness.

In conclusion, TianJi Robot assisted tPELD was proved feasible and effective. We need more cases to demonstrate the accuracy and reliability of this procedure.

\section{REFERENCES}

[1] Yeung A T, Tsou P M. Posterolateral endoscopic excision for lumbar disc herniation: Surgical technique, outcome, and complications in 307 consecutive cases[J]. Spine (Phila Pa 1976),27(7):722-731,2002.

[2] Hoogland T, Schubert M, Miklitz B, et al. Transforaminal posterolateral endoscopic discectomy with or without the combination of a low-dose chymopapain: a prospective randomized study in 280 consecutive cases[J]. Spine (Phila Pa 1976),31(24):E890-E897,2006.

[3] Ruetten S, Komp M, Godolias G. An extreme lateral access for the surgery of lumbar disc herniations inside the spinal canal using the full-endoscopic uniportal transforaminal approach-technique and prospective results of 463 patients[J]. Spine (Phila Pa 1976),30(22):2570-2578,2005.

[4] Anichini G, Landi A, Caporlingua F, et al. Lumbar Endoscopic Microdiscectomy: Where Are We Now? An Updated Literature Review Focused on Clinical Outcome, Complications, and Rate of Recurrence[J]. Biomed Res Int,2015:417801,2015.

[5] Sairyo K, Egawa H, Matsuura T, et al. State of the art: Transforaminal approach for percutaneous endoscopic lumbar discectomy under local anesthesia[J]. J Med 
Invest,61(3-4):217-225,2014.

[6] Fan G, Wang T, Hu S, et al. Isocentric Navigation of Percutaneous Endoscopic Transforaminal Discectomy at the L5/S1 Level in Difficult Puncture Cases: A Technical Note[J]. Pain Physician,20(4):E531-E540,2017.

[7] Choi G, Kim J S, Lokhande P, et al. Percutaneous endoscopic lumbar discectomy by transiliac approach: a case report[J]. Spine (Phila Pa 1976),34(12):E443-E446,2009. [8] Wei S, Tao W, Zhu H, et al. Three-dimensional intraoperative imaging with O-arm to establish a working trajectory in percutaneous endoscopic lumbar discectomy[J]. Wideochir Inne Tech Maloinwazyjne,10(4):555-560,2016.

\section{DISCLOSURES}

The authors declare that there is no conflict of interest.

\begin{tabular}{|c|c|c|c|c|c|c|c|c|c|}
\hline No. & $\begin{array}{c}\mathrm{Ag} \\
\mathrm{e}\end{array}$ & $\begin{array}{c}\text { Se } \\
x\end{array}$ & $\begin{array}{l}\text { Leve } \\
1\end{array}$ & $\begin{array}{c}\text { Classificatio } \\
n\end{array}$ & $\begin{array}{c}\text { VAS leg } \\
\text { pain } \\
\text { (before, } \\
1 \mathrm{~d}, 3 \mathrm{~m})\end{array}$ & $\begin{array}{c}\text { ODI } \\
\text { befor } \\
\text { e }\end{array}$ & $\begin{array}{c}\text { ODI } \\
3 \mathrm{~m}\end{array}$ & Macnab & $\begin{array}{c}\text { Complication } \\
\text { s }\end{array}$ \\
\hline 1 & 45 & M & $\mathrm{L} 4 / 5$ & Paracentral & $8,4,2$ & 62 & 22 & Good & $\begin{array}{c}\text { Repetitive } \\
\text { scan }\end{array}$ \\
\hline 2 & 51 & M & $\mathrm{L} 4 / 5$ & Central & None & None & $\begin{array}{c}\text { Non } \\
\mathrm{e}\end{array}$ & None & $\begin{array}{c}\text { Convert to } \\
\text { open }\end{array}$ \\
\hline 3 & 67 & $\mathrm{~F}$ & $\mathrm{~L} 3 / 4$ & Paracentral & $7,3,1$ & 77.8 & $\begin{array}{c}28 . \\
9\end{array}$ & Good & \\
\hline 4 & 66 & F & $\begin{array}{c}\mathrm{L} 5 / \mathrm{S} \\
1\end{array}$ & Paracentral & $6,1,2$ & 62.2 & $\begin{array}{c}17 . \\
8\end{array}$ & $\begin{array}{c}\text { Excellen } \\
\mathrm{t}\end{array}$ & \\
\hline 5 & 46 & M & $\mathrm{L} 4 / 5$ & Paracentral & $9,3,7$ & 82 & 76 & Poor & Recurrence \\
\hline 6 & 35 & $\mathrm{~F}$ & $\mathrm{~L} 4 / 5$ & Paracentral & $7,1,1$ & 64 & 14 & $\begin{array}{c}\text { Excellen } \\
t\end{array}$ & \\
\hline 7 & 49 & $\mathrm{~F}$ & $\mathrm{~L} 4 / 5$ & Paracentral & $8,2,2$ & 80 & 34 & $\begin{array}{c}\text { Excellen } \\
t\end{array}$ & \\
\hline 8 & 73 & $\mathrm{~F}$ & $\mathrm{~L} 4 / 5$ & Paracentral & $7,2,1$ & 75.6 & 40 & Good & \\
\hline 9 & 54 & M & $\mathrm{L} 3 / 4$ & Foraminal & $9, \quad 1,1$ & 84 & 28 & $\begin{array}{c}\text { Excellen } \\
t\end{array}$ & \\
\hline $\begin{array}{c}\text { Ave } \\
.\end{array}$ & 54 & & & & $\begin{array}{l}\text { 7.6, } \\
2.1,2.1 \\
\end{array}$ & 73.4 & $\begin{array}{c}32 . \\
6\end{array}$ & & \\
\hline
\end{tabular}

Table 1: Results of nine cases of robot-assisted tPELD. 


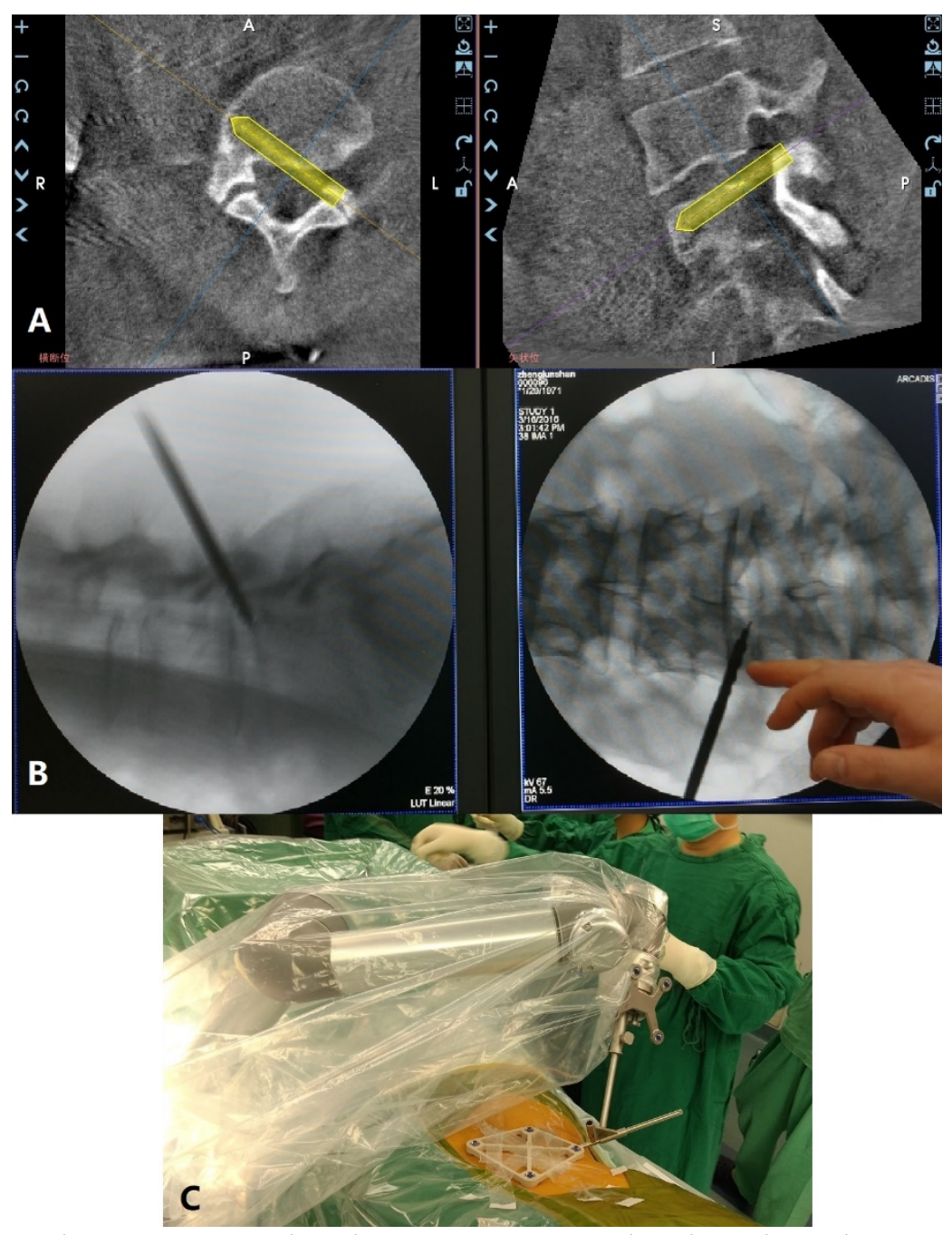

Figure 1. A, Planning system on TianJi Robot demonstrated an ideal trajectory. B, Intraoperative AP and lateral view to make sure ideal position was arrived. C, Instruments were inserted under the guidance of robotic arm. 